La Revista Panamericana de Salud Pública/Pan American Journal of Public Health se complace en publicar cartas de los lectores dirigidas a estimular el diálogo sobre los diversos aspectos de la salud pública en las Américas, así como a esclarecer, discutir o comentar de manera constructiva las ideas expuestas en la revista. Las cartas deben estar firmadas por el autor y especificar su afiliación profesional y dirección postal. Cuando se trate de comentarios sobre un artículo que requieren contestación del autor, se procurará conseguir esa respuesta con el fin de publicar ambas cartas. La Redacción se reserva el derecho de editar las cartas recibidas y resumirlas para mejorar su claridad.

The Revista Panamericana de Salud Pública/Pan American Journal of Public Health publishes letters from readers for the purpose of stimulating dialogue on various aspects of public health in the Americas and of constructively clarifying, discussing, and critiquing the ideas expressed throughout its pages. Letters should be signed by the author and include his or her professional affiliation and mailing address. If a commentary on a given article requires a reply from the author, an effort will be made to obtain the reply and to publish both letters. The editorial team reserves the right to edit all letters received and to condense them so as to improve their clarity.

\section{UN ESTUDIO DIGNIFICANTE: LA SALUD PÚBLICA SIGUE CON VIDA}

\section{Señor Editor:}

He aceptado con beneplácito emitir algunos criterios sobre la importancia del trabajo realizado por mis distinguidos colegas y dilectos amigos, el Dr. Miguel San Sebastián y la Dra. Anna-Karin Hurtig, porque considero que, sin lugar a dudas, las investigaciones realizadas por ellos a lo largo de varios años de su fructífera presencia en el Ecuador constituyen un ejemplo de ese tipo de investigación que tanta falta hace en los países donde la ciega lógica del lucro, al colocarse por encima del bien colectivo, está provocando consecuencias funestas en la salud colectiva. Estas consecuencias no solo han afectado masivamente a las condiciones de vida y ecológicas de las generaciones presentes, sino que dejarán una marca en las futuras generaciones.

Pero más allá de un simple y formal reconocimiento a dicha obra - que muchos centros de investigación, como el que dirijo, y un amplio número de organizaciones sociales del Ecuador estamos prestos a brindar cuantas veces sea necesario-, el motivo de mayor trascendencia que inspira esta carta es el de resaltar los estudios de esa pareja de infatigables científicos, como un paradigma del tipo de investigación que debería inspirar el ejercicio y la enseñanza de la salud pública en América Latina y el mundo entero.
En mis obras más recientes he reiterado una crítica a las entidades de gobierno, a las universidades, e incluso a las agencias de cooperación internacional que han permitido que el pensamiento y la práctica de la salud pública dejen de ser un instrumento para la valoración crítica de los modelos económico-sociales y la construcción de un proyecto alternativo de salud. Los gobiernos latinoamericanos de las sociedades que se llaman democráticas — con las excepciones dignificantes de Cuba, actualmente de Venezuela, y algunos gobiernos municipales como los de Ciudad de México, Porto Alegre, Rosario y Montevideo-, han acogido fórmulas económicas y sociales inspiradas en una lógica que prioriza la rentabilidad económica por encima del interés colectivo $y$, lo que es peor, han supeditado sus planes en campos como la educación, la salud y la seguridad social a las ideas y conveniencias de los grandes negocios. En ese tipo de escenarios la salud pública de la región, reconocida en décadas anteriores por su valiente y pertinaz defensa de los derechos económicos, sociales y culturales en que se sustenta una salud integral, y renombrada por sus empeños para defender la seguridad social y el sistema de salud como derechos humanos irrenunciables, ahora se ha dejado domesticar por esa lógica perversa y cicatera de focalizar servicios y paquetes mínimos, con las mismas triquiñuelas y subterfugios que inspiran a los redactores de la llamada "letra chica" de los seguros privados, que es la que desnuda todas las brechas e 
insuficiencias del modelo privado de bienestar social y de salud.

En medio de ese escenario vergonzoso de claudicación y amansamiento, construido o apoyado por muchas universidades y organizaciones, y trabajado con el lamentable concurso también de técnicos, investigadores y profesores universitarios latinoamericanos, brillan estudios como el de San Sebastián y Hurtig, por su indagación penetrante; por su metodología rigurosa - solo limitada por la escasez de recursos-; pero por sobre todo, por su efecto dignificante y esperanzador. En el estudio "Oil exploitation in the Amazon basin of Ecuador: a public health emergency" [La explotación petrolera en la cuenca amazónica del Ecuador: una emergencia para la salud pública] (1), los incisivos recursos de la ciencia han sido puestos al servicio del esclarecimiento de los efectos de una colosal agresión a la vida humana y a la biodiversidad de una de las reservas estratégicas más importantes de la humanidad. La indagación minuciosa de fuentes documentales, la construcción rigurosa de instrumentos de encuesta, los análisis epidemiológicos certeros de las huellas detectables del impacto, la formulación de recomendaciones concretas para iniciar la remediación y concretar medidas preventivas, se efectúan con esa destreza y mesura de quienes dominan el oficio y demuestran que no es tan verdadera aquella sospecha de nuestros pueblos, de que los círculos de la llamada "excelencia académica" están siempre reñidos con el bien común y cedidos al poder.

Lo felicito a usted, señor editor, y por su intermedio a la Revista Panamericana de Salud Pública, por haber acogido este tipo de trabajo que pone en evidencia que sigue habiendo científicos de la salud pública —algunos preferimos llamarla salud colectiva - que no han renegado de los principios neohumanistas, ni han perdido la brújula en esta hora siniestra de la humanidad, ni se han apartado de la tradición enaltecedora de nuestro campo.

Jaime Breilh, MD, MSc, PhD

Director Ejecutivo

Centro de Estudios y Asesoría en Salud

Quito, Ecuador

\section{REFERENCIA}

1. San Sebastián M, Hurtig AK. Oil exploitation in the Amazon basin of Ecuador: a public health emergency. Rev Panam Salud Publica. 2004;15(3):205-11.

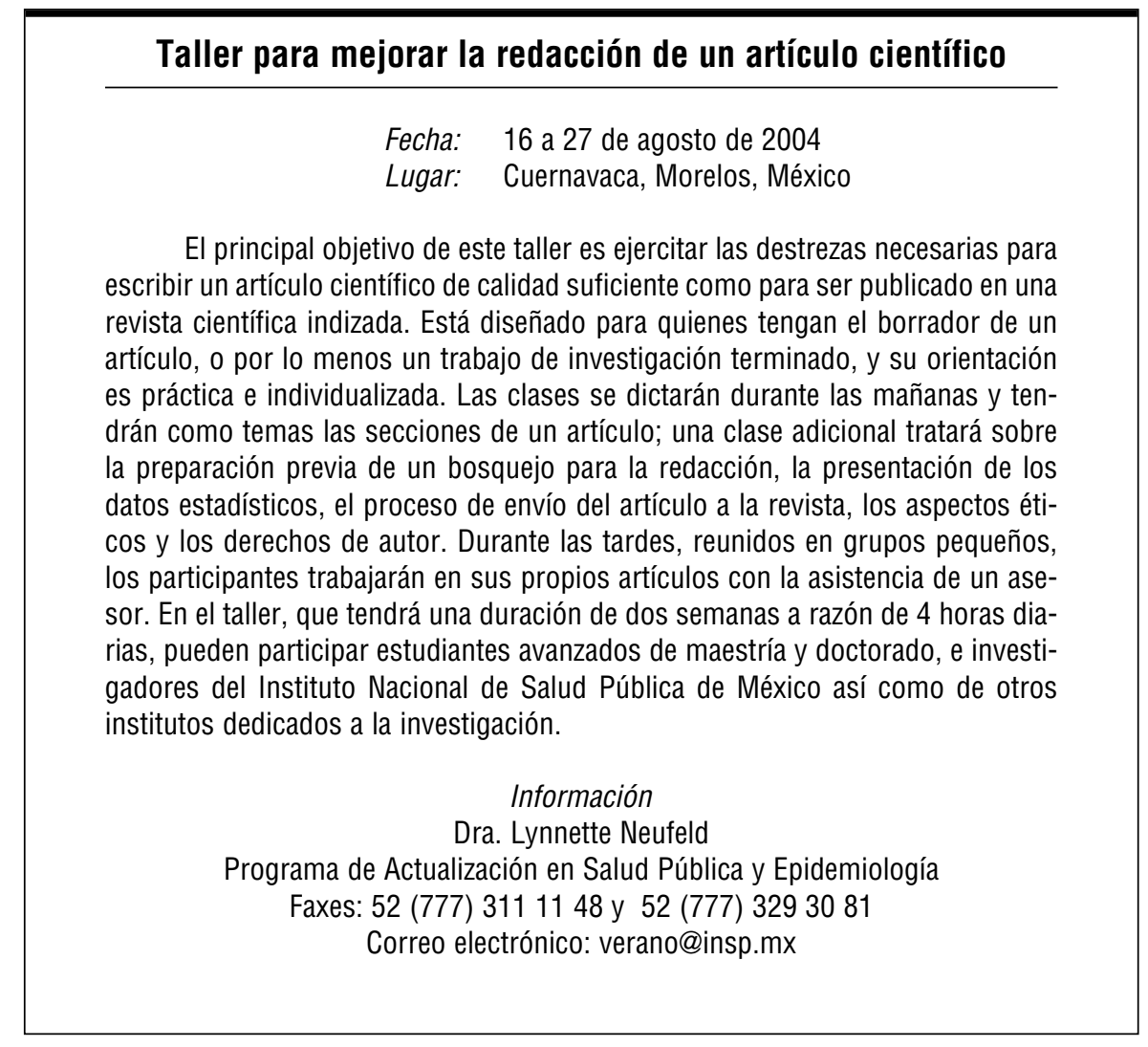

